\title{
Story stimuli for creating false beliefs about the world
}

\author{
ELIZABETH J. MARSH \\ Duke University, Durham, North Carolina
}

\begin{abstract}
Fiction is not always accurate, and this has consequences for readers. In laboratory studies, the reading of short stories led participants to produce story errors as facts on a later test of general knowledge (Marsh, Meade, \& Roediger, 2003). The present article describes these story stimuli in detail, so that interested researchers will be able to use the stimuli and change them as needed for particular research projects. This article provides instructions for using the stories and suggestions for modifying them; it is a manual for one way of creating suggestibility. The full set of stories and reading comprehension questions may be downloaded from www.psychonomic.org/archive/.
\end{abstract}

Fictional stories often take place in real places, make references to actual people, and occur in familiar political and temporal contexts. Educators often take advantage of the link between fiction and the real world (e.g., Dubeck, Bruce, Schmuckler, Moshier, \& Boss, 1990), in part because they believe fictional materials to be inherently interesting to students. By definition, however, fiction is not tied to truth. Although fictional sources may contain correct information about the world, fictional content may also contradict the real world. As such, fiction may be a source of false beliefs about the world. Laboratory studies support this assertion; reading short stories containing errors affects participants' behavior. For example, students who read short stories that contained such statements as "mental illnesses are contagious" shifted their self-reported beliefs to be more consistent with story statements (Gerrig \& Prentice, 1991; Prentice, Gerrig, \& Bailis, 1997). Reading false facts slows verification of well-known true facts, suggesting that the two are integrated in memory (e.g., Peterson \& Potts, 1982).

\section{Background on Archived Stories}

In my own work, story reading led to production of story errors on later tests of general world knowledge (Marsh, Meade, \& Roediger, 2003). High levels of suggestibility were observed. After reading misinformation in the stories, students answered more than $35 \%$ of related general knowledge questions with misinformation,

This work was supported by a Collaborative Activity Award from the James S. McDonnell Foundation. I thank Michelle Meade for her help with early versions of the stories, Karen Mitchell for useful comments on a draft of this paper, and Holli Sink for assistance with manuscript preparation. Correspondence concerning this article should be addressed to E. J. Marsh, Psychological and Brain Sciences, Duke University, 9 Flowers Drive, Box 90086, Durham, NC 27708-0086 (e-mail: emarsh@psych.duke.edu). as compared with a baseline of less than $10 \%$. Prior reading of misinformation also led to fewer questions answered correctly than baseline-suggesting that fiction's errors interfered with the ability to produce previously known answers, rather than affecting performance only when participants had no idea of the answer.

The present paper describes in more detail the materials used in Marsh et al. (2003) and how to adapt them for different research purposes. These materials yield robust misinformation effects, across stories and across experiments, allowing for statistically powerful within-subjects manipulations of all variables (e.g., delay or ease of questions). The basic effect reaches significance with fewer than 20 participants. Hence, these materials could be used to study a number of different research problems, such as the variables that affect suggestibility (e.g., individual differences and social context), how people represent information from fictional sources, and the processes underlying memory misattributions.

\section{Procedure}

The participants were tested in small groups ranging from 1 to 5 people. The study was introduced as a reasoning experiment. There were three phases: story reading, a filler task, and a general knowledge test.

In Phase I, the reading phase, the participants were instructed to read a series of fictional stories. On the basis of pretesting, the participants were given up to $5 \mathrm{~min}$ to read each story; they were given a warning after $3.5 \mathrm{~min}$ had elapsed. They were instructed to read carefully, since after each story they would answer comprehension questions. The first question was always "did you finish reading the story," followed by plot questions. Across experiments, the participants completed different numbers of reading question cycles; early work included nine cycles (Marsh et al., 2003), but more recent work included only one, due to time constraints (Marsh, Balota, \& Roediger, in press). In some experiments, the same story was read 
Table 1

For Each Item, the Story It Appeared in, the Corresponding Number of the Question in the Nelson and Narens (1980) Norms (in the Columns Labeled N\&N\#), and the Correct and Misinformation Answers

\begin{tabular}{|c|c|c|c|c|c|c|}
\hline \multirow[b]{2}{*}{ Story } & \multicolumn{3}{|c|}{ Easy Questions } & \multicolumn{3}{|c|}{ Hard Questions } \\
\hline & N\&N\# & Correct & Misinformation & N\&N\# & Correct & Misinformation \\
\hline \multirow[t]{4}{*}{ Art } & 13 & Ruby & Amethyst & 153 & London & Dublin \\
\hline & 55 & Venice & Padua & 203 & Florence & Rome \\
\hline & 62 & Siamese & Angora & 258 & Frankfort & Louisville \\
\hline & 89 & Sistine & Duomo & 267 & Wood & Green \\
\hline \multirow[t]{4}{*}{ Bear } & 3 & Hibernation & Migration & 168 & Ahab & Bligh \\
\hline & 47 & Prune & Date & 178 & Polaris & Orion \\
\hline & 83 & Venison & Veal & 206 & Cartographers & Geographers \\
\hline & 109 & Sputnik & Mir & 295 & Post & Lindbergh \\
\hline \multirow[t]{4}{*}{ Doctor } & 18 & Insomnia & Narcolepsy & 161 & Hippocrates & Socrates \\
\hline & 26 & Dermatologist & Pathologist & 196 & Dover & Wilmington \\
\hline & 76 & Plasma & Platelets & 197 & Barnard & Barnes \\
\hline & 105 & Nightingale & Barton & 270 & Jenner & Salk \\
\hline \multirow{4}{*}{ Inventor } & 20 & Franklin & Edison & 144 & Morse & Bell \\
\hline & 42 & Mercury & Silicon & 172 & Fulton & Whitney \\
\hline & 64 & Einstein & Newton & 207 & Manhattan & Los Alamos \\
\hline & 108 & Curie & Pasteur & 247 & Ambergris & Epidermis \\
\hline \multirow[t]{4}{*}{ Letters } & 23 & Revere & Hancock & 140 & Clavicle & Humerus \\
\hline & 67 & Booth & Oswald & 263 & Andersonville & Chancellorsville \\
\hline & 68 & Gable & Grant & 281 & Brady & Adams \\
\hline & 80 & Decibel & Ampere & 292 & Meade & Grant \\
\hline \multirow[t]{4}{*}{ Ocean } & 22 & Mayflower & Godspeed & 155 & Sextant & Telescope \\
\hline & 43 & Pacific & Atlantic & 232 & Sirius & North Star \\
\hline & 63 & Atlantis & Pompeii & 252 & Anemometer & Barometer \\
\hline & 98 & Fathom & Knot & 275 & Berlin & Coward \\
\hline \multirow[t]{4}{*}{ Scouting } & 36 & Yellowstone & Yosemite & 174 & Mariana Trench & Midatlantic Range \\
\hline & 65 & Jupiter & Saturn & 209 & Hillary & Scott \\
\hline & 71 & Hibachi & Raku & 222 & Ural & Alps \\
\hline & 88 & Chameleon & Iguana & 239 & Bannister & Owens \\
\hline \multirow[t]{4}{*}{ Star } & 44 & Pluto & Neptune & 143 & Copernicus & Galileo \\
\hline & 50 & Sahara & Gobi & 146 & Architect & Artist \\
\hline & 53 & Armstrong & Glenn & 152 & Pegasus & Sagittarius \\
\hline & 70 & Meteors & Asteroids & 188 & Eagle & 10 \\
\hline \multirow[t]{4}{*}{ Travel } & 29 & Gold & Platinum & 166 & India & Pakistan \\
\hline & 46 & Japan & China & 211 & Helsinki & Oslo \\
\hline & 54 & Moscow & St. Petersburg & 225 & Greece & Hungary \\
\hline & 91 & Bogart & Tracy & 231 & Cooperstown & Indianapolis \\
\hline
\end{tabular}

more than once (Marsh et al., 2003); in such cases, the second set of comprehension questions was different from the first.

Phase II involved a filled delay; across experiments, this was as short as 2 min and as long as a week.

Phase III involved the general knowledge test containing both the critical questions and other filler questions taken from the Nelson and Narens (1980) norms. The participants were warned against guessing and were told to draw a line through the answer space if they were unable to answer the question.

\section{Materials}

In Marsh et al. (2003), nine different short stories were developed in order to investigate participants' reliance on fictional sources. Each story was two to three singlespaced pages and contained characters, dialogue, and plot. The stories were clearly fictional in nature and covered the following topics: a hunting trip in Alaska, an art thief, a couple's 50th wedding anniversary, a student's first day of medical school, a science fair, letters written during the U.S. Civil War, a cruise, a girl scout troop, and a job at a planetarium. One story ("Scouting") is appended in its entirety. All of the stories can be found in the Behavior Research Methods, Instruments, \& Computers Web archive of stimuli and data, featured in this special issue.

Embedded within each story were peripheral references to items from the Nelson and Narens (1980) norms. Half of the items were defined as high prior knowledge; on average, $70 \%$ of the students in Nelson and Narens's study answered these items correctly. Half of the items were defined as low prior knowledge; on average, $15 \%$ of the students in Nelson and Narens's study were able to answer these correctly. In the Scouting example (see the Appendix), the question "what is the largest planet" is considered easy (high prior knowledge), since in the norming study, $65 \%$ of the respondents answered it correctly. In contrast, the question "Who was the 1 st man to run a mile in under 4 minutes" is considered hard (low 
Table 2

\begin{tabular}{|c|c|c|c|c|c|c|c|}
\hline \multirow[b]{3}{*}{ Story } & \multirow{2}{*}{\multicolumn{3}{|c|}{$\begin{array}{r}\text { Effects Observed as a Function of St } \\
\text { Benefit After Reading } \\
\text { Correct in Story } \\
\end{array}$}} & \multirow{2}{*}{\multicolumn{2}{|c|}{$\begin{array}{c}\text { From Marsh et al. (200 } \\
\text { Cost After Reading } \\
\text { Misinformation in Story } \\
\end{array}$}} & \multicolumn{2}{|c|}{ Experiment 2) } \\
\hline & & & & & & $\begin{array}{r}\mathrm{I} \\
\text { Misinfor }\end{array}$ & $\begin{array}{l}\text { in } \\
\text { Production }\end{array}$ \\
\hline & Difficulty & Once & Twice & Once & Twice & Once & Twice \\
\hline \multirow[t]{2}{*}{ Art } & Easy & .08 & .08 & -.09 & -.17 & -.08 & .08 \\
\hline & Hard & .34 & .42 & .00 & -.08 & .17 & .58 \\
\hline \multirow{2}{*}{ Bear } & Easy & .17 & .33 & -.17 & -.17 & .17 & .17 \\
\hline & Hard & .00 & .41 & -.42 & .08 & .09 & .25 \\
\hline \multirow[t]{2}{*}{ Doctor } & Easy & .00 & .08 & -.17 & -.17 & .33 & .50 \\
\hline & Hard & .16 & .58 & -.09 & .25 & .33 & .33 \\
\hline \multirow[t]{2}{*}{ Inventor } & Easy & .08 & .17 & -.25 & -.58 & .33 & .25 \\
\hline & Hard & .41 & .42 & -.09 & .00 & .25 & .42 \\
\hline \multirow[t]{2}{*}{ Letters } & Easy & .25 & .25 & -.16 & -.08 & .17 & .34 \\
\hline & Hard & .08 & .34 & -.08 & .08 & .25 & .25 \\
\hline \multirow[t]{2}{*}{ Ocean } & Easy & .25 & .41 & .08 & -.09 & .00 & .25 \\
\hline & Hard & .25 & .58 & .00 & .00 & .50 & .25 \\
\hline \multirow[t]{2}{*}{ Scouting } & Easy & .08 & .59 & -.09 & .09 & .00 & .25 \\
\hline & Hard & .00 & .25 & .00 & -.17 & .08 & .33 \\
\hline \multirow[t]{2}{*}{ Star } & Easy & .25 & .17 & .00 & -.25 & .00 & .17 \\
\hline & Hard & .17 & .42 & .09 & .00 & .08 & .17 \\
\hline \multirow[t]{2}{*}{ Travel } & Easy & .25 & .42 & .00 & -.41 & .17 & .67 \\
\hline & Hard & .09 & .59 & -.25 & -.25 & .33 & .58 \\
\hline
\end{tabular}

Note-The "Benefit" columns reflect the average boost in proportion correct after reading the correct answer once or twice in the story, as compared with the neutral baseline (correct - neutral). The "Cost" columns reflect the average change in proportion correct after reading the misinformation once or twice in the story, as compared with the neutral baseline (misleading - neutral). The final set of columns shows the increase in production of the target misinformation answers as a function of reading them once or twice in the stories, as compared with baseline.

prior knowledge), since only $7 \%$ of Nelson and Narens's participants answered it correctly.

Within each story, fact framing was manipulated. That is, a reference was made to each critical item, and across participants, the item appeared in three different fact frames: correct, neutral, and misleading. For example, consider the question "in which national park is the geyser Old Faithful located?" References to this item appeared in the story "Scouting." The troop leader made the following statement in the correct condition: "So here's what I am suggesting: a trip to Yellowstone where we can hike and see the famous geyser Old Faithful." In the neutral condition, she referred to the item but made no suggestion about which national park the geyser resides in: "So here's what I am suggesting: a trip to a national park where we can hike and see the famous geyser Old Faithful." This neutral reference can be used as a baseline for measuring both the positive and the negative effects of story reading (as will be described below). In the misleading condition, she referred to the geyser and suggested the wrong park as its location: "So here's what I am suggesting: a trip to Yosemite where we can hike and see the famous geyser Old Faithful."

Table 1 provides a summary of the items used in Marsh et al. (2003). For each story, the correct-misinformation pairings, whether each was considered easy or hard, and the number of the corresponding question in the Nelson and Narens (1980) norms are listed. For example, the Yellowstone/Yosemite pairing refers to Question 36. By looking up Question 36 in the norms, the researcher will obtain the full wording of the question. The norms also contain other information that may be of interest to the researcher, such as the latency of recall and feeling-ofknowing ratings.

\section{Measuring Effects of Story Reading}

There are several different ways of measuring the effects of story reading. A benefit is defined as improved performance on the final general knowledge test after having read correct answers in the story, as compared with having read neutral references. Costs of story reading involve fewer correct answers on the final test after having read misinformation in the stories, as compared with when neutral frames had been read. A third measure is also very interesting, involving the production of target misinformation on the general knowledge test at higher levels following reading of misinformation than after reading of the neutral frames. Table 2 shows examples of these three measures broken down by story, easy versus hard questions, and one versus two story readings (these data are from Marsh et al., 2003, Experiment 2). Note these data are not meant to be standardized norms for the stories. A new experiment run with the same stories might yield different results, depending on the prior knowledge of particular participants. Rather, the point is to highlight that reading any of these stories would impact performance on the final general knowledge test.

Researchers should note that the neutral condition does not have to be used as the baseline. That is, the stories can be changed in such a way that all items appear in either the correct or the misleading frame, and the baseline can be performance on questions for never-read stories (e.g., Marsh, 2003; Marsh et al., 2003, Experiment 3 ). The experimenter would then simply counter- 
balance across participants which stories were read. Depending on which baseline is used, the stories should contain multiples of four or six story items ( 2 difficulty levels $\times 2$ or 3 fact framings). Each of the archived stories contains eight items, to display as many as possible, but researchers may not wish to use all the items if the neutral baseline is chosen.

\section{Using the Archive}

Stories are archived in both word and rich text format, so that the researcher can easily manipulate fact framing (and which facts are included in any given story). The story in the Appendix will give experimenters an idea of how the archived materials will appear. The critical items appear in the stories in bold type and underlined. For each critical item, the first reference is always correct, the second is neutral, and the third is misleading; these references are separated by slashes (if the middle reference is a series of Xs, that means the neutral version involves no additional text and that the sentence is grammatically correct without the inclusion of the correct or misinformation answers). The researcher should counterbalance fact framing across participants, so that each item appears once per participant.

The format of the archived stories means that a number of variations are possible. As has already been noted, for example, the experimenter could choose to use a never-read baseline, rather than the neutral frames. The experimenter could also modify the number of items included in any given story. As an example of this, the archive includes extra versions of two of the stories, "Summer Star Search" and "Inventor," which were modified for a short study in which the participants had time only to read one story; the extra items were included for power reasons (Marsh et al., in press). An experimenter could come up with additional (or different) misinformation items and embed them in the stories. For example, one might want to manipulate the plausibility of the misinformation. Returning to the earlier example, Old Faithful could be incorrectly placed in Yosemite (a plausible lure) or Central Park (an implausible lure). Or the experimenter might decide not to bother with the easy items and to add more hard items. There are many possibilities, and the format of the archived materials makes these changes easy.

In short, the materials available on the Web site should prove of use to researchers interested in a number of different problems. Studying the processes underlying fiction reading requires creative stimuli, and it is my hope that others will be able to use these, rather than have to create their own.

\section{REFERENCES}

Dubeck, L. W., Bruce, M. H., Schmuckler, J. S., Moshier, S. E., \& Boss, J. E. (1990). Science fiction aids science teaching. The Physics Teacher, 28, 316-318.

Gerrig, R. J., \& Prentice, D. A. (1991). The representation of fictional information. Psychological Science, 2, 336-340.

Marsh, E. J. (2003, November). The persistence of facts learned from fiction. Poster presented at the 44th Annual Meeting of the Psychonomic Society, Vancouver.

Marsh, E. J., Balota, D. A., \& Roediger, H. L., III (in press). Learning facts from fiction: The effects of healthy aging and early stage dementia of the Alzheimer's type. Neuropsychology.

Marsh, E. J., Meade, M. L., \& Roediger, H. L., III (2003). Learning facts from fiction. Journal of Memory \& Language, 49, 519-536.

NeLSON, T. O., \& NARENS, L. (1980). Norms of 300 general-information questions: Accuracy of recall, latency of recall, and feeling-of-knowing ratings. Journal of Verbal Learning \& Verbal Behavior, 19, 338-368.

Peterson, S. B., \& Potts, G. R. (1982). Global and specific components of information integration. Journal of Verbal Learning \& Verbal Behavior, 21, 403-420.

Prentice, D. A., Gerrig, R. J., \& Bailis, D. S. (1997). What readers bring to the processing of fictional texts. Psychonomic Bulletin $\& R e$ view, 4, 416-420.

\section{ARCHIVED MATERIALS}

The following materials may be accessed through the Psychonomic Society's Norms, Stimuli, and Data archive, http://www.psychonomic. org/archive/.

To access these files, search the archive for this article using the journal (Behavior Research Methods, Instruments, \& Computers), the author's name (Marsh) and the publication year (2004).

\section{FILE: Marsh-BRMIC-2004.zip}

DESCRIPTION: The compressed archive file contains four folders:

The folder marsh_reading_questions_(word) contains 18 files, two for each of the nine archived stories: questions_art1.doc, questions_art2.doc, questions_bear1.doc, questions_bear2.doc, questions_doctor1.doc, questions_doctor2.doc, questions_inventor1.doc, questions_inventor2.doc, questions_letters1.doc, questions_letters2.doc, questions ocean1.doc, questions_ocean2.doc, questions_scouting1.doc, questions_scouting2.doc, questions_star1.doc, questions_star2.doc, questions_travel1.doc, questions_travel2.doc. Each is a word file (generated by Microsoft Office 2000 for PC) and contains four questions: a reading completion check plus three plot questions. The folder marsh_reading_questions_(text) contains the same 18 files in rich text format.

The folder marsh_stories_(word) contains 12 files: an instruction file on the formatting of facts in the stories (story_instructions.doc), the nine original stories (art.doc, bear.doc, doctor.doc, inventor.doc, letters.doc, ocean.doc, scouting.doc, star.doc, travel.doc) plus stories modified to contain additional items (inventor_modified.doc, star_modified.doc). Each story file (generated by Microsoft Office 2000 for PC) contains a single story with critical items in bold type and underlined; the first reference is always correct, the second is neutral, and the third is misleading; these references are separated by backslashes. If the middle reference is a series of Xs, that means the neutral version involves no additional text (rather, the sentence should read fine without the inclusion of the correct or misinformation answers). The folder marsh_stories_(text) contains the same 12 files in rich text format.

AUTHOR's E-MAIL ADDRESs: emarsh@psych.duke.edu.

AUTHOR's WEB SITE: http://psychweb.psych.duke.edu/department/ marsh/. 


\section{APPENDIX}

One complete story is included here. The critical items are in bold type and underlined for the ease of the reader. For each critical item, the first reference is always correct, the second is neutral, and the third is misleading; these references are separated by backslashes. If the middle reference is a series of Xs, that means that the neutral version involves no additional text (rather, the sentence should read fine without the inclusion of the correct or misinformation answers). The reader should counterbalance fact framing across participants, so that each item appears once per participant, in one format, but across participants each item appears in all three frames. Since the stories are archived both in rich text and word formats, it will be easy for the reader to remove the bold/underlining formatting prior to using the materials in an experiment. It will also be easy for the reader to remove references to the frames not used in a given version and to create different versions of each story for counterbalancing purposes.

\section{SCOUTING}

Mrs. Roose was the perfect mother-she was the head of the PTA, volunteered in the classroom, organized all the car pools, made exquisite elaborately decorated cakes, and never missed one of her sons' many sporting events. As the proud mother of four sons, she was most used to building model train sets, cheering at basketball games, and listening to the drums. She felt rather at a loss when her niece Abigail came to live with them for a few months while her parents went abroad. Abigail was a shy, sweet girl who loved everything pink and played with Barbie dolls constantly. She was also an avid girl scout, and so Mrs. Roose felt the need to take over her sister's role as troop leader. It was exactly the kind of thing Mrs. Roose enjoyed - a position of authority which required organizational skills and also involved a sense of competition - for surely Mrs. Roose's troop could earn more merit badges than the other troops in the area!

So one Thursday afternoon Mrs. Roose's home was invaded for the first time ever by 12 little girls. Mrs. Roose was a bit disconcerted to discover that troop meetings normally involved eating girl scout cookies, discussing how they could sell more cookies, and planning how they would use their cookie money to go to an amusement park in a few months.

"But girls ..." said a perplexed Mrs. Roose slowly. "It's not girl scout cookie season. However are you selling cookies?"

Silence. Finally a little girl with pigtails suggested "they're last year's cookies?"

Mrs. Roose took a deep breath. "We can't sell last year's cookies-won't they be stale?" At this comment, 12 heads looked down at the cookies they were eating, hesitated, took a bite, and shrugged.

"Well, I think it's a good idea to branch out what this troop does. How about merit badges. How many did you earn last year?" Mrs. Roose's question was greeted by silence. "How many badges do you have?" tried Mrs. Roose again.

"Auntie, we just do cookies. We don't have any badges" explained Abigail authoritatively.

Mrs. Roose was stunned into silence for a minute, and then she started talking quickly. "Girls! There is so much more to scouting than cookie sales. You need to have some experiences and earn some badges! So here's what I am suggesting: a trip to Yellowstone / a national park / Yosemite where we can hike and see the famous geyser Old Faithful. We can work on several badges: camping, ecology, hiking, rocks \& minerals-is there a rocks \& minerals badge?" 12 blank faces looked at Mrs. Roose in response to this question.

Mrs. Roose threw herself into planning the camping trip. She scheduled it down to the minute each day, cramming in as many badge-relevant activities as possible. She decided that if they arrived early enough on a Friday night, they could work on cooking over an open fire rather than using the Hibachi, / XXXXX / the Raku, a small Japanese outdoor stove (cooking over a fire counted toward two different badges whereas using a stove only counted for 1 badge). After it got dark they could search the skies for a view of the largest planet, Jupiter / XXXXX / Saturn (astronomy badge). If they stayed two days in the park, one day could be spent hiking and the other doing things in camp like learning to tie knots.

To prepare the troop for the trip, she forbid even the mention of cookies at meetings. Instead, she had the troop prepare physically by running laps and doing push-ups. They also climbed a lot of stairs to simulate going up a mountain.

Abigail was the first to question this approach. "Auntie, it's not like we're Hillary / XXXXX / Scott trying to climb Everest for the first time ever-we're just going to hike for 3 hours on a relatively flat trail. We're not climbing Denali in Alaska or hiking through the Urals / mountains / Alps separating Europe and Asia."

A girl with asthma chimed in: "Yeah, it's like you want us to be like Bannister / that guy / Owens who ran the first sub 4minute mile. We're just not going to do that. You should be glad we can jog a mile!"

Mrs. Roose ignored these complaints and pushed on with trip preparations. She made sure each girl had the appropriate gear for the weekend. She purchased extra food, insect repellent, flashlights, and toilet paper. She started alternating the workout sessions with ecology classes after discovering one scout couldn't recognize even the most familiar of wildflowers. The girls remained moderately interested in the ecology classes until they strayed far afield from North American forests and Mrs. Roose started lecturing on the deepest part of the ocean, the Mariana Trench / XXXXX / the Midatlantic Range (because it was related to the ocean badge). While the girls complained about all these non-cookie meetings, they all kept coming, because they wanted desperately to go on the camping trip. Any girl who missed a preparatory meeting was not allowed on the trip.

The big weekend arrived. Troop 417 arrived at the park on schedule, and spent Friday evening completing seven activities that counted toward four different badges. Mrs. Roose firmly enforced the pre-set bedtime, making the girls retire to their tents promptly at 10 p.m. even though they wanted to stay up and tell ghost stories around the camp fire (telling stories didn't count toward any badges).

Saturday morning dawned, a beautiful morning for a hike. The troop was at the trailhead by 11 a.m. Mrs. Roose took ten minutes to explain the route in detail: by walking at a twenty minute per mile pace, and stopping at 3 viewpoints for twenty minutes each, they could cover the entire 6-mile trail in 3 hours and be back at the campsite in time to chop firewood before dinner (and thus complete the last requirement for the camping badge). Mrs. Roose was very pleased with this plan, and she dealt 


\section{APPENDIX (Continued)}

effectively with all complaints at the first viewpoint when the girls wanted to watch the waterfall for more than twenty minutes.

They were about halfway through their fourth mile when Abigail started shrieking and pointing her finger at a low tree bush. "Look!" she screamed.

Girls rushed over to where Abigail was standing, and stood in awe, staring at a small green lizard frozen among the leaves. Excitement grew when another girl found the same lizard on a log, except in a brownish color.

"What are they?" wondered one girl aloud.

"It's a chameleon / a lizard / an iguana that changes its color to match its surroundings" said Abigail importantly.

Mrs. Roose smiled at the girls "All right, dears, it's a nice lizard but it's time to move along now."

But no one paid any attention to her. Girl after girl discovered yet another lizard, in various shades of green and brown, and the delighted girls settled down to watch. They sat on tree stumps, on fallen logs, on moss. One dug out her camera, another took out her sketch pad, and still others thumbed through brand-new guide books trying to find facts on the lizards.
"Girls!" Mrs. Roose's voice was a bit shrill. "We have a schedule to keep! Come along now."

"But Auntie" cajoled Abigail. "You can't schedule time for things like lizards. You just have to enjoy them when they come along. I thought this was what scouting was all about!"

Mrs. Roose stood there with her hands on her hips, watching, and slowly repeating the thought "This is what scouting is all about ... this is what scouting is all about ... this is what scouting is all about ... this is it!" Somehow she had missed the target almost as badly as her cookie-fixated sister. It was true that scouting was not just about selling cookies, but it was also true that scouting was more than just merit badges. It didn't matter if they didn't chop firewood today - they could chop firewood any day, but lizards like this wouldn't always be so easy to find. And Mrs. Roose, the perfect mother, was always willing to admit when she was wrong. So she put down her backpack on a rock, and sat and watched her charges for an hour while they played in the woods. And even though they didn't have time to chop firewood, Mrs. Roose felt like she had been a good troop leader that day.

(Manuscript received December 16, 2003;

revision accepted for publication July 17, 2004.) 